\title{
Comparison of Fine Needle Aspiration Cytology in Thyroid Lesions using The Bethesda System for Reporting Thyroid Cytopathology with Ultrasonography using Thyroid Imaging Reporting and Data System
}

\author{
Sudeep Regmia ${ }^{\mathrm{a} d}$ Archana Tiwari ${ }^{\mathrm{b}, \mathrm{d}}$ Rupesh Sharma ${ }^{\mathrm{c}, \mathrm{d}}$
}

\begin{abstract}
:
Introduction: Thyroid nodule is a common presentation. The estimated prevalence of thyroid nodules is $4-7 \%$ by clinical examination and 50-60\% on ultrasonographic (USG) evaluation. Most are benign without any symptoms or cosmetic concerns. Only around 5\% are found to be malignant. Methods: This prospective study evaluated a total of 54 patients with thyroid lesions presenting to Otorhinolaryngology, Surgery and Internal Medicine out-patient departments of a tertiary hospital for a period of nine months. The thyroid lesions were categorized into different categories using Thyroid Imaging Reporting and Data System (TIRADS) by USG and The Bethesda System for Reporting Thyroid Cytopathology (TBSRTC) by fine needle aspiration (FNA). The agreement between TIRADS and TBSRTC was evaluated using Cohen's kappa statistics. Results: By FNA, 68.5\% were benign lesions whereas 7.4\% were malignant. Follicular Neoplasm (FN) or Suspicious for FN and Suspicious for Malignancy category comprised $5.6 \%$ each. $1.9 \%$ of the lesions showed Atypia of Unknown Significance (AUS). $11.1 \%$ of the lesions were nondiagnostic or unsatisfactory for evaluation. Overall agreement between the cases by USG and FNA using the TIRADS and TBSRTC respectively was $77.77 \%$. There was a substantial agreement between the diagnosis made by these systems, kappa $(\kappa)=.633(95 \%$ CI, 0.41 to $0.85, \mathrm{p}<0.05)$. Conclusion: This study observed a substantial agreement between the diagnosis made by TIRADS on USG and TBSRTC on FNA. Our study advocates the stratification of thyroid lesions according to TIRADS so that only suspicious lesions undergo FNA.
\end{abstract}

Keywords: Fine Needle Aspiration, TBSRTC, Thyroid Nodules, TIRADS

\section{INTRODUCTION:}

Thyroid nodule is a common presentation. The prevalence of thyroid nodules is estimated to be $4-7 \%$ by clinical examination and $50-60 \%$ on ultrasonographic (USG) evaluation.[1,2] Most of these nodules are benign without any symptoms or cosmetic concerns.[1] Out of these thyroid nodules, only around $5 \%$ are found to be malignant.[3]

\author{
Submitted: 24 November, 2018 \\ Accepted: 12 December, 2018 \\ Published: 30 December, 2018 \\ a - Lecturer, Department of Pathology \\ b - Assistant Professor, Department of Pathology \\ c- Lecturer, Department of Radiodiagnosis \\ d- Lumbini Medical College and Teaching Hospital, Pravas, Palpa
}

Corresponding Author:

Sudeep Regmi

e-mail: sudeepregmi10@gmail.com

ORCID: http://orcid.org/0000-0002-3207-515X
Therefore, the major concern about thyroid nodule is to rule out or confirm malignancy by USG and Fine Needle Aspiration (FNA). Surgical removal of all thyroid nodules is unnecessary and should be stratified by the use of USG and FNA.[4]

The Bethesda System for Reporting Thyroid Cytopathology (TBSRTC) is a standardized, category based evaluation of thyroid FNAs to provide a uniform diagnostic terminology for pathologists. $[3,5,6]$ TBSRTC also provides an implied risk of malignancy and recommends clinical management of the thyroid lesions according to the category.

\footnotetext{
How to cite this article:

Regmi S, Tiwari A, Sharma R. Comparison of Fine Needle Aspiration Cytology in Thyroid Lesions using The Bethesda System for Reporting Thyroid Cytopathology with Ultrasonography using Thyroid Imaging Reporting and Data System. Journal of Lumbini Medical College. 2018;6(2):5 pages. DOI: $10.22502 / j 1 \mathrm{mc} . v 6 i 2.274$. Epub: 2018 Dec 30.
} 
$[3,4,5]$ The six diagnostic categories suggested by TBSRTC are: I) Non-diagnostic or unsatisfactory; II) Benign; III) Atypia of Undetermined Significance (AUS) or Follicular Lesion of Undetermined Significance (FLUS); IV) Follicular Neoplasm (FN) or Suspicious for Follicular Neoplasm; V) Suspicious for Malignancy; VI) Malignant.[5]

The Thyroid Imaging Reporting and Data System (TIRADS), first proposed by Horvath et al.[7] was established to standardize the scoring system of thyroid USG and provide recommendations for using FNA and to improve appropriate patient management. $[4,8,9]$ The TIRADS categories as suggested by American College of Radiology (ACR) and known as ACR TI-RADS are: I) Benign; II) Not Suspicious; III) Mildly Suspicious; IV) Moderately Suspicious; V) Highly Suspicious.[4]

This study attempts to observe the concordance between the TIRADS and TBSRTC on thyroid lesions of patients presenting to our hospital.

\section{METHODS:}

This was an observational cross-sectional study conducted in the Department of Pathology, Lumbini Medical College and Teaching Hospital, Palpa, Nepal. We evaluated a total of 54 patients with thyroidlesions presenting to the Otorhinolaryngology, Surgery and Internal Medicine 0ut-patient Departments from March, 2018 to November, 2018 for a period of nine months. Seven patients who were referred to the Pathology Department for FNA had not undergone USG evaluation, hence were not included in the study.

Ethical approval was obtained from the Institutional Review Committee (IRC-LMC) prior to commencement of the study.

The USG evaluation was done by a single radiologist, and the lesion was categorized as per TIRADS. If the lesion was primarily evaluated by another radiologist, the radiologist (co-investigator) categorized the lesion into TIRADS.

All the FNAs were performed by either of the two pathologists (principal Investigator and co-investigator), and the lesions were categorized according the TBSRTC. All the cases were reviewed by both pathologists.

Statistical analysis was done using kappa statistics with a $95 \%$ confidence, and concordance between TIRADS and TBSRTC was evaluated.
For the purpose of statistical analysis, category I was omitted from both TIRADS and TBSRTC, and cases of TBSRTC VI category were retained in the TBSRTC $\mathrm{V}$ as there is no corresponding category i.e. TIRADS VI. The categories for analysis were as follows:

- TBSRTC II and TIRADS II: "BENIGN"

- TBSRTC III and TIRADS III: "PROBABLY BENIGN"

- $\quad$ TBSRTC IV and TIRADS IV: "SUSPICIOUS FOR MALIGNANCY"

- TBSRTC V and TIRADS V: "PROBABLY MALIGNANT"

All the data management and statistical analysis were done using Statistical Package for Social Sciences $\left(\mathrm{SPSS}^{\mathrm{TM}}\right)$ software, version 16.

\section{RESULTS:}

We studied a total of 54 patients with thyroid lesions presenting to the Department of Pathology who underwent USG evaluation. Age of the patients ranged from 17 to 88 years with a mean of $50.74 \pm 17.8$ years. $92.6 \%$ were females and $7.4 \%$ were males. Most of the patients presented with Right sided thyroid lesion $(40.7 \%)$ followed by Bilateral (31.5\%), Left $(20.4 \%)$, and Midline (4.4\%). A majority of the lesions were nodular $(85.2 \%)$, and the rest $14.8 \%$ were diffuse. The maximum diameter of nodular thyroid lesions ranged from 10 to $86 \mathrm{~mm}$ with a mean of $30.15 \pm 15.63 \mathrm{~mm}$ by USG.

By FNA, 68.5\% were benign lesions whereas $7.4 \%$ were malignant. Follicular Neoplasm (FN) or Suspicious for FN and Suspicious for Malignancy category comprised $5.6 \%$ each. $1.9 \%$ of the lesions showed AUS. $11.1 \%$ of the lesions were nondiagnostic or unsatisfactory for evaluation.

The distribution of TIRADS and TBSRTC categories in all thyroid lesions is shown in Figure 1.

The malignant lesions (TBSRTC-VI) comprised $7.4 \%$ cases. These cases were revised as TBSRTC-V for statistical purpose, as TIRADS has no corresponding category and TIRADS-V shows the highest risk of malignancy by USG. The non-diagnostic or unsatisfactory cases comprising $11.1 \%$ of the cases were omitted from the statistical calculations. Overall agreement between the cases by USG and FNA using the TIRADS and TBSRTC respectively was $77.77 \%$. Cohen's kappa was run to determine the agreement between the TIRADS and TBSRTC categories. There was a substantial agreement between the diagnosis made by these 


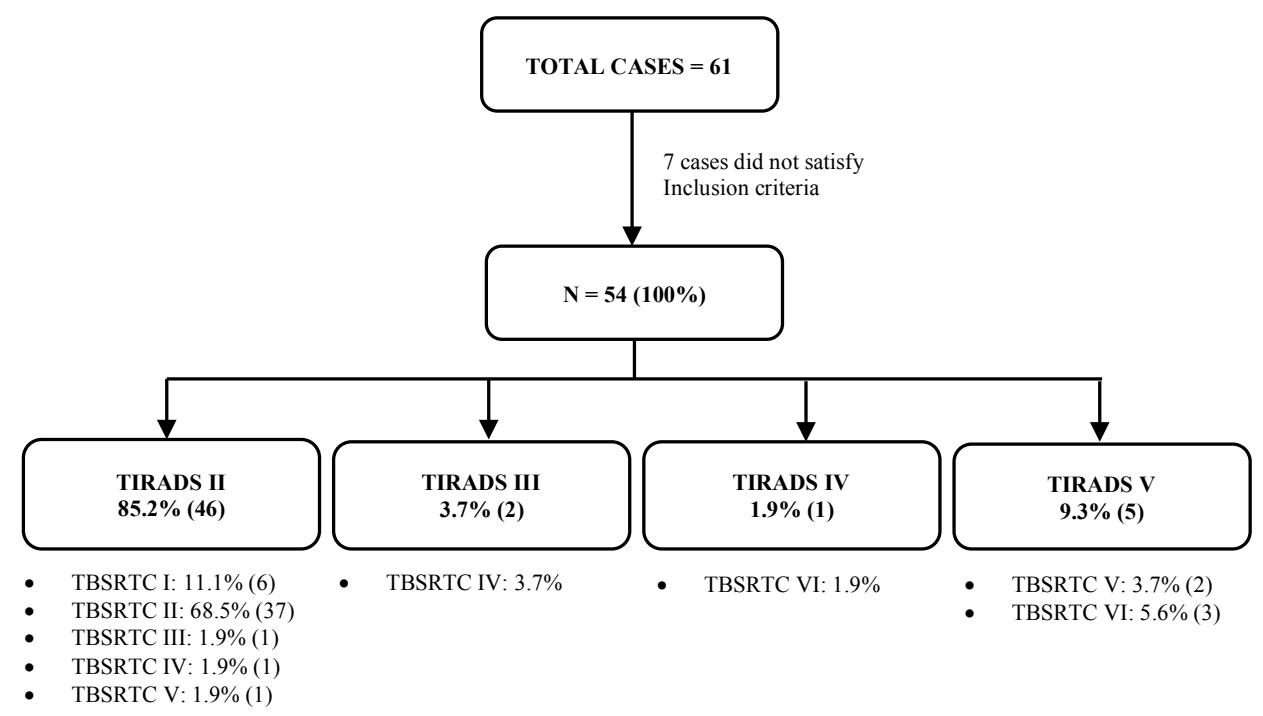

Fig. 1. Distribution of Cases by TIRADS and TBSRTC

systems, kappa $(\kappa)=.633(95 \% \mathrm{CI}, 0.41$ to 0.85 , $\mathrm{p}<0.05$ ).

\section{DISCUSSION:}

This study intended to analyze the agreement between USG evaluation of thyroid lesions using TIRADS and cytological evaluation using TBSRTC. Management of thyroid lesions depends on clinical history, thyroid function test (TFT), USG and FNA. [1] FNA is a tool to safely, accurately and costeffectively evaluate the thyroid lesions and to decide a management protocol.[10,11] However, not all thyroid lesions need surgical interventions. Ideally, after a clinical evaluation and TFT, USG should be performed to stratify the thyroid lesions and FNA should be performed only on suspicious lesions. $[12,13,14]$
Majority of the patients in our study were females. Other similar studies also reported predominance of female population presenting with thyroid lesions.[8,9,12] Increased prevalence of thyroid lesions in females, according to studies, might be related to hormonal influences of estrogen and progesterone. Rate of thyroid nodules increases proportionately with ionizing radiation or occupational exposures.[13]

Our study observed $11.1 \%$ non-diagnostic (ND) or unsatisfactory (USF) i.e. TBSRTC-I cases. ND/USF cases range from $1.8 \%$ to $23.6 \%$ of all thyroid FNAs.[3] Thyroid FNAs are ND/USF mostly due to cystic nature, sampling error or poor preparation techniques. Around 7\% of thyroid lesions will be ND/USF even on repeat FNAs.[12,13,14] To reduce the chances of false-negative rate, TBSRTC advise

Table 1. Diagnostic Categories with Their Implied Risk of Malignancy, and Recommended Clinical Management

\begin{tabular}{llll}
\hline & Risk of & Risk of & \\
Diagnostic Category & Malignancy if & Malignancy if & Usual Management \\
& NIFTP $\neq$ CA $(\%)$ & NIFTP=CA (\%) & \\
Nondiagnostic or Unsatisfactory & $5-10$ & $5-10$ & Repeat FNA with USG guidance \\
Benign & $0-3$ & $0-3$ & Clinical and Sonographic follow-up \\
Atypia of Undetermined Significance & $6-18$ & $10-30$ & Repeat FNA, molecular testing, or lobectomy \\
Follicular neoplasm or suspicious for & $10-40$ & $25-40$ & Molecular testing, lobectomy \\
a follicular neoplasm & $45-60$ & $50-75$ & Near-total thyroidectomy or lobectomy \\
Suspicious for malignancy & $94-96$ & $97-99$ & Near-total thyroidectomy or lobectomy \\
$\begin{array}{l}\text { Malignant } \\
\text { NIFTP - Noninvasive follicular thyroid neoplasm with papillary-like nuclear features } \\
\text { CA - Carcinoma }\end{array}$ & &
\end{tabular}


that FNA smears should have at least six group of well-preserved, well-stained, and well-visualized thyroid follicular epithelial cells and each group should be composed of ten cells, preferably on a single slide.[5,15] Periakaruppan et al.[12] observed $8 \%$ unsatisfactory cases on FNA in their study. The implied risk of malignancy on ND/USF is $5-10 \%$, as laid down by TBSRTC.[5] However, a systematic review shows malignancy rates of $0-26 \%$ on followup FNAs.[16] American Thyroid Association (ATA) recommends using a USG guidance for repeat FNA and correlate with suspicious features on USG. ATA suggests that partially cystic nodules yielding ND aspirate need close observation or surgical excision, whereas surgery should be the considered if lesions are solid.[3,14]

In our study, $7.4 \%$ of the cases were malignant on FNA. If we include the cases in TIRADS- $V$ and TBSRTC-V, the prevalence rate of malignant lesions on thyroid is $9.25 \%$, including the highly suspicious lesions for malignancy. However, no histopathological correlation was made for the suspicious lesions on FNA. According to Kilfoy BA et al.[17], thyroid malignancies constitute $1-5 \%$ of thyroid lesions among women and around $2 \%$ in men. There is an increasing trend of malignancy of thyroid lesions all over the world. This can be attributed to the availability of diagnostic facilities. [18] A capital based study from Nepal by Bista M et al.[19] reported a $15.68 \%$ prevalence of thyroid malignancy on FNA.

Overall, our study observed $77.77 \%$ agreement in diagnosis between TIRADS and TBSRTC. Study of Singaporewalla RM et al.[20] suggested an agreement of $83 \%$ between these two systems of thyroid lesion evaluation. In our study, there was a substantial agreement between TIRADS and TBSRTC as suggested by kappa statistics. Similar to our study, Vargas-Uricoechea H et al. showed a good concordance between TIRADS and TBSRTC.[8] However, these findings of our study should be validated by a larger scale study.

To establish an uniformity in reporting purpose and for a clear communication between the pathologists and clinicians, TBSRTC has proposed different diagnostic categories for thyroid lesions on FNA. For each diagnostic category, TBSRTC provides implied risk of malignancy and recommended clinical management (Table 1).[5]

TIRADS endorsed by the ACR recommends FNA to be performed in lesions which are suspicious for malignancy. They have suggested FNA as per the TIRADS criteria as follows[4]:

- TIRADS II (Not Suspicious) - No FNA

- TIRADS III (Mildly Suspicious) - FNA if $\geq$ $2.5 \mathrm{~cm}$, follow-up $(\mathrm{F} / \mathrm{U})$ if $\geq 1.5 \mathrm{~cm}$

- TIRADS IV (Moderately Suspicious) - FNA if $\geq$ $1.5 \mathrm{~cm}, \mathrm{~F} / \mathrm{U}$ if $\geq 1 \mathrm{~cm}$

- TIRADS V (Highly Suspicious) - FNA if $\geq 1 \mathrm{~cm}$, $\mathrm{F} / \mathrm{U}$ if $\geq 0.5 \mathrm{~cm}$

\section{CONCLUSION:}

Our study observed a substantial agreement between the diagnosis made by TIRADS on USG and TBSRTC on FNA. Thyroid lesions should be stratified according to TIRADS and the suspicious lesions should only undergo FNA. This protocol will be beneficial to avoid unnecessary FNAs on thyroid lesions.

\section{Conflict of interest:}

The authors declare that no competing interests exist.

\section{Source of funds:}

No funds were available. 


\section{REFERENCES:}

1. Gharib H, Papini E, Garber JR, Duick DS, Harrell RM, Hegedüs L, Paschke R, Valcavi R, Vitti P. American Association of Clinical Endocrinologists, American College of Endocrinology, and Associazione Medici Endocrinologi medical guidelines for clinical practice for the diagnosis and management of thyroid nodules-2016 update. Endocrine practice. 2016 May;22(s1):1-60. PMID: 27167915 DOI: 10.4158/EP161208.GL [Publisher Full Text]

2. Gharib H, Papini E, Paschke R, Duick D, Valcavi R, Hegedüs L, Vitti P. American Association of Clinical Endocrinologists, Associazione Medici Endocrinologi, and European Thyroid Association medical guidelines for clinical practice for the diagnosis and management of thyroid nodules. Endocrine Practice. 2010 May 1;16(Supplement 1):1-43. PMID: 20543550 DOI: 10.4158/10024.GL [Publisher Full Text]

3. Wu HH, Swadley MJ. The Bethesda system for reporting thyroid cytopathology: into the clinic. Pathology and Laboratory Medicine International. 2015 Sep 1;2015(1):4754. DOI: 10.2147/PLMI.S59827 [Publisher Full Text]

4. Tessler FN, Middleton WD, Grant EG, Hoang JK, Berland LL, Teefey SA, Cronan JJ, Beland MD, Desser TS, Frates MC, Hammers LW. ACR thyroid imaging, reporting and data system (TI-RADS): white paper of the ACR TI-RADS committee. Journal of the American college of radiology. 2017 May 1;14(5):587-95. PMID: 28372962 DOI: 10.1016/j. jacr.2017.01.046 [Publisher Full Text]

5. Cibas ES, Ali SZ. The 2017 Bethesda System for Reporting Thyroid Cytopathology. Thyroid. 2017 Nov;27(11):13416. PMID: 29091573 DOI: $10.1089 /$ thy.2017.0500

6. Al Dawish MA, Robert AA, Muna A, Eyad A, Al Ghamdi A, Al Hajeri K, Thabet MA, Braham R. Bethesda system for reporting thyroid cytopathology: A three-year study at a tertiary care referral center in Saudi Arabia. World journal of clinical oncology. 2017 Apr 10;8(2):151-7. PMID: 28439496 DOI: 10.5306/wjco.v8.i2.151 [Publisher Full Text]

7. Horvath E, Majlis S, Rossi R, Franco C, Niedmann JP, Castro A, Dominguez M. An ultrasonogram reporting system for thyroid nodules stratifying cancer risk for clinical management. The Journal of Clinical Endocrinology \& Metabolism. 2009 May 1;94(5):1748-51. PMID: 19276237 DOI: 10.1210/jc.2008-1724 [Publisher Full Text]

8. Vargas-Uricoechea H, Meza-Cabrera I, Herrera-Chaparro J. Concordance between the TIRADS ultrasound criteria and the BETHESDA cytology criteria on the nontoxic thyroid nodule. Thyroid research. 2017 Dec;10(1):1. PMID: 28184253 DOI: 10.1186/s13044-017-0037-2 [Publisher Full Text]
9. Hong MJ, Na DG, Baek JH, Sung JY, Kim JH. Cytologyultrasonography risk-stratification scoring system based on fine-needle aspiration cytology and the Koreanthyroid imaging reporting and data system. Thyroid. 2017 Jul 1;27(7):953-9. PMID: 28463597 DOI: $10.1089 /$ thy.2016.0603

10. Rossi M, Lupo S, Rossi R, Franceschetti P, Trasforini G, Bruni S, Tagliati F, Buratto M, Lanza G, Damiani L, Degli Uberti E. Proposal for a novel management of indeterminate thyroid nodules on the basis of cytopathological subclasses. Endocrine. 2017 Jul 1;57(1):98-107. PMID: 27623969 DOI: $\underline{10.1007 / s 12020-016-1105-4}$

11. Moon HJ, Kim EK, Yoon JH, Kwak JY. Malignancy risk stratification in thyroid nodules with nondiagnostic results at cytologic examination: combination of thyroid imaging reporting and data system and the Bethesda System. Radiology. 2015 Jan;274(1):287-95. PMID: 25133852 DOI: $\underline{10.1148 / \text { radiol.14140359 [Publisher Full Text] }}$

12. Periakaruppan G, Seshadri KG, Krishna GV, Mandava R, Sai VP, Rajendiran S. Correlation between ultrasoundbased TIRADS and Bethesda system for reporting thyroid-cytopathology: 2-year experience at a tertiary care center in India. Indian journal of endocrinology and metabolism. 2018 Sep-Oct;22(5):651. PMID: 30294576 DOI: 10.4103\%2Fijem.IJEM $27 \quad 18$ [Publisher Full Text]

13. Popoveniuc G, Jonklaas J. Thyroid nodules. Medical Clinics. 2012 Mar 1;96(2):329-49. PMID: 22443979 DOI: 10.1016/j.mcna.2012.02.002 [Publisher Full Text]

14. Agarwal S, Jain D. Thyroid cytology in India: contemporary review and meta-analysis. Journal of pathology and translational medicine. 2017 Nov;51(6):533-47. PMID: 28994274 DOI: 10.4132\%2Fjptm.2017.08.04 [Publisher Full Text]

15. Ha SM, Ahn HS, Baek JH, Ahn HY, Chung YJ, Cho BY, Park SB. Validation of Three Scoring Risk-Stratification Models for Thyroid Nodules. Thyroid. 2017 Dec 1;27(12):1550-7. DOI: $10.1089 /$ thy. 2017.0363

16. Valderrabano P, McIver B. Evaluation and management of indeterminate thyroid nodules: the revolution of risk stratification beyond cytological diagnosis. Cancer Control. 2017 Dec 25;24(5):1073274817729231. PMID: 28975825 DOI: $\underline{\text { 10.1177\%2F1073274817729231 [Publisher }}$ Full Text]

17. Sánchez JF. TI-RADS classification of thyroid nodules based on a score modified according to ultrasound criteria for malignancy. Revista Argentina de Radiología. 2014;78(3):138-48. [Publisher Full Text] 